\title{
BMJ Open Beyond the diagnosis: a qualitative exploration of the experiences of persons with hepatitis B in the Accra Metropolis, Ghana
}

\author{
Charles Ampong Adjei, ${ }^{1}$ Florence Naab, ${ }^{2}$ Ernestina S Donkor ${ }^{3}$
}

To cite: Adjei CA, Naab F, Donkor ES. Beyond the diagnosis: a qualitative exploration of the experiences of persons with hepatitis $B$ in the Accra Metropolis, Ghana. BMJ Open 2017;7:e017665. doi:10.1136/ bmjopen-2017-017665

- Prepublication history and additional material for this paper are available online. To view these files, please visit the journal online (http://dx.doi. org/10.1136/bmjopen-2017017665).

Received 23 May 2017 Revised 7 September 2017 Accepted 20 September 2017

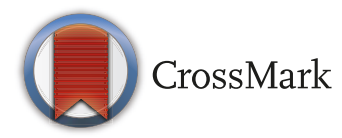

${ }^{1}$ Department of Nursing, Valley View University, Accra, Ghana ${ }^{2}$ Department of Maternal and Child Health, School of Nursing, College of Health Sciences, University of Ghana, Accra, Ghana

${ }^{3}$ Department of Maternal and Child Health, School of Nursing, College of Health Sciences, University of Ghana, Accra, Ghana

Correspondence to Charles Ampong Adjei; cadjei@vvu.edu.gh

\section{ABSTRACT}

Objective This study explored the experiences of people with hepatitis B in the Accra metropolis.

Design The study employed qualitative exploratory descriptive design with purposive sampling technique. Data were collected through face-to-face interview and transcribed verbatim. The data were analysed using content analysis.

Settings Participants were recruited from one government and one mission hospital in Ghana

Participants Fourteen individuals aged between 26 and 45 years with hepatitis B infection were interviewed. Results The findings of the study showed that people with hepatitis B in the Accra metropolis were unclear about the impact of their infection. Furthermore, they experienced psychological and social problems especially when they were initially informed about their hepatitis B status. Sadness, fear, shock, shame and disbelief were some of the experiences reported by participants. Coping strategies adopted include religiosity, denial and lifestyle modification.

Conclusions it is, therefore, necessary as a country to integrate hepatitis B counselling into the already existing HIV structures in the health delivery system to offer support for individuals diagnosed with hepatitis B. Furthermore, it is important to draw lessons from the process used in the diagnosis of HIV, particularly in ensuring that people provide consent for being tested.

\section{INTRODUCTION}

Hepatitis B viral infection remains one of the most important public health concerns worldwide. About 248 million people are documented positive of hepatitis B globally. ${ }^{1}$ In 2010, hepatitis B was found to be the 10th leading cause of global deaths and about $50 \%$ of deaths as a result of liver cancer were attributed to the infection. ${ }^{2}{ }^{3}$ The consequences of the infection such as liver cirrhosis, hepatic failure and hepatocellular carcinoma are well documented to cause approximately 780000 deaths annually on a global scale. ${ }^{245}$

Although no global estimate of economic impact of hepatitis B was found, it is well documented that hepatitis B imposes an
Strengths and limitations of this study

This study is the first to explore the experiences of people with hepatitis B in Ghana and Africa.

- However, the small sample size makes the finding not generalisable to the entire people with hepatitis $B$ in Ghana.

- Additionally, the outcome of this study will assist in developing population-based surveys to quantify the extent of knowledge of people with hepatitis B in order to develop appropriate public health interventions in Ghana.

- The study is limited by the recruitment of only people within the age bracket of 26-45 years and few men participating in the study.

- The participants have lived with their diagnosis between 1 and 5 years.

enormous economic burden on patients, families, health system and the society at large spanning from healthcare cost, cost of treatment and work loss. ${ }^{6-8}$ For instance, a study done in Vietnam showed that the total cost of treatment of hepatitis B and its complication was estimated to be US $\$ 4.4$ million nationally and the patient suffers a huge cost of care when the condition becomes more severe. ${ }^{8}$

Currently, hepatitis B is receiving international recognition and attention from WHO and the World Health Assembly with recent emphasis on four axes: raising awareness, promoting partnership and mobilising resources; developing evidenced-based policy and data for action; prevention of transmission; and increasing access to screening, care and treatment. ${ }^{9}$ This attention is demonstrated by the development of the first WHO guideline for prevention, care and treatment of persons with hepatitis B. ${ }^{10}$ More so, the health target for the sustainable development goal three which seeks to combat hepatitis by $2030^{11} 12$ add onto the global priority on viral hepatitis. 
Ghana is endemic with hepatitis B with about $8 \%-20 \%$ of the adult population estimated to be living with the infection. ${ }^{1314}$ The long-term consequences of the infection are also reported to account for $42.9 \%(n=70)$ of liver cirrhosis in the country. ${ }^{15}$ As part of Ghana's response to hepatitis B prevention and control, hepatitis B vaccine was added to the Expanded Programme on Immunisation in January 2002. ${ }^{16}$ This new vaccine was combined with (Diptheria, Pertussis, Tetanus) DPT, and Haemophilus influenza type $\mathrm{b}$ commonly referred to as pentavalent vaccine. ${ }^{16}$ The vaccine is administered to children at 6,10 and 14 weeks after birth. Generally, hepatitis B testing and vaccination are offered for a fee in most healthcare facilities in Ghana because it is not covered by the National Health Insurance Scheme. In recent times, some hospitals have implemented mandatory screening of pregnant women as part of antenatal care services, but not universal nationwide. ${ }^{17}$ Only a few hospitals provide specialised liver clinic for people with hepatitis B in Ghana.

Global evidence indicates that living with hepatitis B is associated with social and psychological afflictions such as stigma, discrimination, anxiety, depression and low quality of life. ${ }^{18-25}$ However, in spite of the high prevalence (ie, 8\%-20\%) of hepatitis B in Ghana, no study was identified by the researchers that have documented the experiences of persons with hepatitis B. This study, therefore, sought to understand the psychological and social impact of hepatitis B on those diagnosed with the infection including their coping strategies in the Accra Metropolis to inform policy and programme design.

\section{METHODS}

\section{Study design}

Qualitative exploratory descriptive design was used. This design was appropriate because according to Grove $e t a l^{26}$ an individual experience is unique to him/her and can be in the best position to give an account and meanings to their own experiences. Furthermore, a qualitative investigation was imperative given the lack of previous research investigating the lived experience of people with hepatitis $B$ in Africa generally and Ghana specifically, and the need to ensure that the perspective of people with hepatitis B could be properly investigated.

\section{Study setting}

The study was conducted in the Greater Accra region. It is the smallest among the 10 administrative regions in Ghana. It occupies a total land area of $3245 \mathrm{~km}^{2} .{ }^{27}$ Greater Accra region is found in the South-Central part of Ghana and shares boundaries with the Eastern region to the North, Central region to the West, Volta region to the East and the Gulf of Guinnea to the South. ${ }^{27}$ According to the 2010 population and housing census, about 4010050 people reside in the region. ${ }^{27}$ One mission hospital and one government hospital in the Accra metropolis were used as data collection sites. These hospitals were selected because they are district hospitals that offer hepatitis B screening, vaccination and support.

\section{Participant's eligibility \\ Inclusion criteria}

Participants were included in the study if they were 18 years and above and had tested hepatitis B (HBsAg) positive for 6 months or more and consented to participate.

\section{Exclusion criteria}

People living with hepatitis B who were not medically stable were excluded from the study. These are individuals who were terminally ill and had less energy to go through the interview session.

\section{Sampling method and sample size}

Purposive sampling technique was employed to select people with hepatitis $\mathrm{B}$ who met the inclusion criteria. A purposive sampling technique is a non-probability sampling method in which a researcher selects participants based on the inclusion criteria and purpose of the study. In this case, the researchers were interested in informants who were willing to give information about their experience. ${ }^{28}$ This was, however, appropriate for the study because it assisted the researchers to gain an insight into a new area and understood complex experiences. ${ }^{26}$ Fourteen out of the 18 participants contacted agreed to participate in the study. Those who refused to take part cited time constraint as reason. Data were saturated at the 11 participants. Data saturation is the point at which no new information is obtained during an interview. ${ }^{29}$ Data collection continued despite saturation to determine new emerging issues.

\section{Data collection tool}

Face-to-face in-depth interview was conducted. This was achieved by using semistructured interview guide to collect data from each participant. The guide had both open-ended and close-ended questions which allowed the researchers to probe until in-depth information was obtained from each participant. The guide was designed based on the study objectives and literature and it is included as online supplementary file 1. Questions focused on feeling after diagnosis, perception of life after testing hepatitis B positive, effect of a positive result and coping strategies adopted. In addition, field note was taken during the interview session.

\section{Data collection procedure}

Participants' recruitment commenced after ethical clearance was obtained from the Institutional Review Board of Noguchi Memorial Institute for Medical Research of the University of Ghana. Also, permission from the management of the data collection sites was obtained. Individuals diagnosed with hepatitis B were identified through the hospitals register with the assistance of healthcare providers. Potential participants were contacted through telephone calls. The purpose of the study was explained 
in detail to those who were contacted. A convenient time and venue for each participant was arranged after they had consented to participate in the study. Those agreed to take part in the study were given an informed consent form to sign. Furthermore, consent of each participant was sought to record the interview session using audiotape recorder after its rationale of record keeping for reference purpose has been explained to them. Data were collected between January and February 2016 mostly in the homes of the participants. Each interview lasted between 45 and $60 \mathrm{~min}$. One participant was emotionally disturbed (tears were flowing down her cheek) when recounting her experiences. Interview was halted and counselling was provided until the participant became emotionally stable and consented to continue. The interviews were conducted by the principal investigator (CAA).

\section{Data analysis}

Data were analysed using content analysis technique. The researchers played and listened to the audio-taped interviews and transcribed verbatim to familiarise themselves with the data. The three researchers coded the data individually, followed by series of group discussions of the codes and the generation of the major themes. The researchers, however, ensured that there were linkages between the themes and the codes. Subthemes were created from the themes and the study findings are presented using the themes and the subthemes.

\section{RESULTS}

\section{Demographic characteristics}

The study recruited a total of 14 persons with hepatitis B. Participants were within the age range of 26-45 years and they were all Ghanaians. Seven of the participants had tertiary level education, five had a primary level education and two had no formal education. Two participants were single, three divorced after being tested hepatitis $\mathrm{B}$ positive and the remaining nine were still married. Females were 11 with only 3 males. The participants have been living with the infection for 1-5years. None of the participants were on regular monitoring or prescribed treatment. Participants were diagnosed either at the time of pregnancy as part of their antenatal care routine laboratory investigations or through outreach services in churches or school programmes. Pseudonyms are used to ensure anonymity of participants.

\section{Individual level factors}

This theme describes the individual level factors that influence one's social and psychological experiences. The study revealed that persons living with hepatitis B suffer various degrees of psychological challenges including sadness, worries, fear, shock, shame and disbelief. Furthermore, lack of awareness of the disease and blame was noted among some study participants.

\section{Lack of awareness}

The findings showed that 9 out of 14 participants were not aware of hepatitis B before they were diagnosed positive. Moreover, those who were aware had some knowledge gap on the impact of their infection. Some participants admitted their ignorance, but others classified the population in general to be deficient of hepatitis B-related information as compare to HIV which is known by many.

As for hepatitis B, I didn't know about it until I got infected. What I knew to be deadly is HIV. It was the laboratory man who educated me about the disease that it is also dangerous (Sozo)

As for HIV we all know about it but this hepatitis B, it is new to us. I only heard about it on radio, but I didn't know what it was (Momo)

\section{Sadness/Worries/Fear}

Most participants reported that they were sad, worried and scared about their hepatitis B positivity. According to them, this psychological trauma was more visible a few days after diagnosis. More so, participants who were aware of hepatitis B and its associated complications manifested more of these symptoms.

Because I have heard about the seriousness of the disease on a radio, I felt so scared and worried. In fact, I started sweating and suddenly became weak in my bones. Fear gripped me so badly that my whole day was spoilt. I was scared until I went on the internet to read about it then I realised it is not as dangerous as HIV as said on the radio. It was after knowing that I became a bit relaxed (Kim)

Participants who knew someone who had died of the disease were very much terrified when they got to know their status.

My friend was told that she has hepatitis B about five years ago. She then started falling ill more often and finally died last year. So when I was told I was hepatitis B positive, I was scared by the result (Maju)

The primary driver of the psychological affliction associated with the infection is the comparison of hepatitis B with the disease HIV. Most participants perceived hepatitis B to be more dangerous than HIV and therefore felt their life will soon come to an end. In addition, the absence of informed consent before testing and inaccurate information given to people who are diagnosed with the infection also contributed to their negative experiences.

I think the sadness is a normal feeling because we hear the disease is more dangerous than HIV so it means that you have a short life. You can die at any time. That makes me sad. I think about my children. What will happen to them if I die and leave them behind? These are the things I think about' (Hani) 
You know, some people say on the radio that hepatitis B is more serious than HIV and I know how people with HIV end up to become. So I was imagining myself being in the worst situation than someone with HIV.....Also, the liver is only one, so if it gets spoilt then that means my life will finish (Kim)

Some participants reported that hepatitis B adverts on radio and television particularly those presented by herbal medicine practitioners did fuel their fear. Undoubtedly, most of the airwaves in Ghana allow herbal practitioners to sell their products on radio and television and therefore it is common to hear myth about hepatitis B being discussed. A participant recounted her experience.

I only think about it (hepatitis B) when I see an advert on television.... Because the way they describe it as very dangerous, I become so scared, especially the herbal medicine sellers. They sound so scary as if you will die tomorrow when infected. At that moment, I get so afraid that as soon as it is over then I become okay (Maju)

\section{Shock/Shame/Disbelief}

The study found that six of the participants were shocked when they were informed of their positive results. This according to them occurred because they were not prepared at the time of testing to receive a positive result. Some participants revealed that they got tested for hepatitis B because per the policy of the hospital they attended for delivery, it was compulsory for every pregnant woman to have hepatitis B screening done.

Well...I felt very bad and was thinking otherwise like how come I have this virus. I was really shocked! (Yoland)

According to Hani, knowing that she was hepatitis B positive was the greatest surprise in her life. She felt that her sense of dignity was lost after she got to know her positive status. She lamented:

Hmmmm! I could not believe it. I was more than confident before the testing that I will be negative. Growing up as a young lady, I never involved in any bad practices such as sleeping with men. I remained a virgin till I married my husband, so I have never thought of being positive. I felt ashamed and shocked! (Hani)

The effects of participants' bitter experiences were noted to affect their job since mental distortions were reported. This was much pronounced in a situation whereby participants were not able to vividly establish the cause of their infection.

Sometimes I lose concentration even at work especially when I remember that I am hepatitis B positive. I sometimes think to see if I can pinpoint the main means that I got the disease. That alone put me into psychological stress (Hani)

\section{Blame}

The majority of the female participants did not hesitate to link their source of infection to their spouse's. According to most of them, their spouses indulge in extra marital affairs and therefore might have gotten themselves infected through their multisexual behaviours. Some even inquired from the healthcare providers to ascertain such possibilities. Maju narrated:

I first asked the nurses if my husband might be the one who has given me the infection but I was told not necessarily because there are so many ways I can get it (Maju)

Furthermore, participants who perceived their partners to be unfaithful in their marriage confidently attributed their source of infection to them. This is well said in the two quotes by Yoland and Maju below:

...I was putting the blame on my husband. I suspected him because when I was with him, he was always flirting with other ladies (Yoland)

I have seen him (husband) many times with other women, so I will not be surprised if he is the one who has given me this dangerous disease. He does not live a clean life. What I mean is that he likes chasing girls (Maju)

However, some of the participants resorted to blaming as a strategy to let their spouses go for hepatitis B test. This was more common among women who suspected their partners to be promiscuous. Although hepatitis B is transmitted predominantly through mother-to-child in the study setting, many believe that it is sexually transmittable like HIV. This explains the reactions of some participants towards their spouses.

I said....You (spouse) need to go for check-up so that we know where it is coming from... whether from you or not? (Yoland)

I only wanted to be sure if my husband is not the one who has given me the disease and therefore I told him to go for the test so that we all understand why? (Hani)

Sozo reported how she finds it difficult to forgive her mother after she got to know of her positive status. According to her, she could have prevented herself from being positive when she tested negative during hepatitis $B$ screening at school. Unfortunately because her parent failed to recognise the significance of hepatitis $B$ vaccination and therefore refused to pay for it, she is now positive 5 years down the line. She lamented:

Hmmm! My story is different. I could have prevented myself from this disease. About five years ago I had the test and it was negative. By then I was in school, 
so I called my mum to inform her about the cost of vaccination, but she said no. That is why I feel that she is the cause of my infection (Sozo)

\section{Coping strategies}

Some of the participants were affected by the diagnosis and therefore resorted to different approaches to cope with it. Others had superstitious belief that they are bewitched by someone and that explains why they are hepatitis B positive. Revelations by some spiritual leaders made others accept the contribution of spirituality to the cause of the disease. Notwithstanding, some participants recognised the disease as a normal occurrence. Religiosity, denial and lifestyle modification are coping strategies used by the participants.

\section{Religiosity}

Religion plays a major role in the life of many Ghanaians. They are quick to attribute the causes of diseases to an evil spirit. For many Ghanaians, God is the determinant of a person's destiny and therefore whatever comes their way are the plans of God concerning their life. This assertion by most of the participants made them believe God for healing and therefore prayed with the hope that they will be healed 1 day.

The day I was informed that I have this disease, all what I said was my enemies had raised a war against me. I went on my knees and prayed that the Lord should deal with them because He is the only one who can fight my battle for me (Kuku)

As for me, I only depend on God for my healing. Sometimes, I go for a Bible and start reading. I do that because I believe God has the power to heal all diseases (Maju)

Some participants depended on words of encouragement from their spiritual leaders to cope with the disease. Yoland shares how her engagement with her pastor calmed her down.

It didn't affect me because we were having our pastor, so we informed him. He prayed about it, and he said the second test shouldn't be positive. I didn't talk about it again and didn't want to put it in my mind that I have this hepatitis B (Yoland)

\section{Denial}

Different people have various ways of dealing with chronic conditions. The study revealed that majority of the participants took off their minds from the disease as a means of coping with it. This was noted as a strategy for many to overcome the stresses associated with the condition.

I take it as normal. I don't think about it. I move my life freely. I did not put it in my mind, so it doesn't move me to sit down and think about it (Momo)
I just brushed it off and not to think about it that I have hepatitis B. The more you put it in your mind, the more you can't even move on in life (Yoland)

Maju also indicated that she avoids listening or watching programmes about hepatitis B because it causes her to think about the disease.

When the advert comes, I take my mind off it (Maju)

\section{Lifestyle modification}

Some participants changed their lifestyle after the diagnosis. This according to them was an attempt to prevent developing serious complications. Intake of alcohol and fatty foods were avoided by many.

Before I got to know I was hepatitis B, I was drinking a lot of alcohol; I mean hard ones like 'Akpeteshie' (local gin). After knowing, I stopped because the nurse said what can kill me is the alcohol since it helps to destroy the liver fast. This made me to be afraid, and I stopped drinking the alcohol. I now feel ok because I know that I will live a longer life [Sozo)

Kora also shared how she has modified her lifestyle after receiving education on hepatitis B from a healthcare provider. She now strictly adheres to foods that are recommended for persons with hepatitis B infection. She had this to say:

Luckily for me, where I attend church, the pastor's wife has a little background of medicine so she always talks about hepatitis B. She has been teaching us how to live if you have it, the food you have to eat and that is what I depend on (Kora)

Furthermore, the study found that some lifestyle changes were a bit of worry to some of the participants. They perceived it as a burden because they have to live with the condition for the rest of their lives.

Sometimes when you go out with friends, there are things you cannot do. You cannot take alcohol, there are foods you don't have to eat then is like restricting yourself from so many things. (Sozo)

\section{DISCUSSION}

This study provides insight into the experiences of people with hepatitis B following their diagnosis. The study found that some participants had knowledge deficit and limited awareness about the impact of hepatitis B before diagnosis. Generally, participants consent were not sought before testing and therefore the outcome of the screening presented various forms of psychological trauma to majority of them. The illness experience made participants to employ different coping strategies including religiosity, denial and lifestyle modification.

Several studies in other countries have documented knowledge deficit among people with hepatitis B. ${ }^{30-34}$ For 
example, Dahl et $a l^{30}$ found that $50 \% \quad(\mathrm{n}=55)$ of people with hepatitis B identified kissing and mosquito bites as sources of hepatitis B transmission. Unlike HIV which is known by approximately $96 \%$ of Ghanaians, ${ }^{35}$ hepatitis B awareness appears to be low in Ghana. Most participants became aware of the infection after their diagnosis. Perhaps, the high campaign programmes carried out over the years on HIV might be the reason underlying this revelation in Ghana. It is, therefore, important to develop and implement a population-based hepatitis $\mathrm{B}$ awareness campaign to augment the effort of the few non-governmental organisations working on hepatitis B project in the country. ${ }^{36}$

Consistent with other studies in Asia, Malaysia and Australia, ${ }^{24} 253738$ this study found that most participants were sad, worried and entertained some fears when they got to know their hepatitis B positive status. This experience was more pronounced among those who were very much aware of the complications associated with the infection such as liver cancer and cirrhosis. Similarly in Malaysia, people with hepatitis B who had knowledge on the consequences of their positive results expressed more fears when compared with those with inadequate knowledge. ${ }^{25}$ This psychological distress occurs because some hepatitis B-positive individuals consider themselves as possible sources of infection to their families and friends. ${ }^{24}{ }^{30}$ Moreover, the assumption of hepatitis B being associated with HIV may be fuelling the fear. It is worth mentioning that there are no clear guidelines on the management of hepatitis B in many healthcare facilities in Ghana and therefore information about what to do next after positive hepatitis B result is not well communicated to clients including follow-up care. This among other things leaves the infected person in a state of confusion after diagnosis. The non-existence of informed consent before hepatitis B testing may explain why some participants experienced psychological problem. There is the need to learn from the experience of the processes used in the diagnosis of HIV for hepatitis B, particularly in ensuring that people provide consent for being tested, and that information about the infection and referral information is provided to people on diagnosis.

Furthermore, some participants experienced shock, disbelief and shame of their status particularly when they were first informed about their positive test result. This corroborates with other related study findings. ${ }^{25} 34$ The reactions of the participants could be explained by the fact that screening was not voluntary for many but rather part of the health facilities protocol which failed to take into consideration pretesting and post-testing counselling. Moreover, the shock and disbelief experience by people with hepatitis B after diagnosis can be speculated to occur because most people with hepatitis B are unable to point out the sources of their infection. ${ }^{32} 37$

The study further found three ways in which people with hepatitis B cope with their disease: religiosity, denial and lifestyle modification. Religiosity plays a significant role in coping with chronic diseases ${ }^{39} 40$ and this is relevant in the context of Ghana where many people hold strong religious belief. Some participants attributed the cause of the disease to the activities of evil spirit and therefore relied on God and their spiritual heads for support. This may have negative effect on the healthcare seeking of people with hepatitis B with such belief and possibly lead to delay in reporting to the clinic for monitoring, care and support. More so, denial of hepatitis B status and its effect were found in the study as shown by the minimum attention participants placed on the infection. Similar study by $\mathrm{Ng} e t a l^{25}$ found that people with hepatitis B adopted a positive mindset as a way of coping with their infection. It is also documented in literature that people with hepatitis $\mathrm{B}$ modified their lifestyle after diagnosis ${ }^{241}$ and the most common lifestyle changes include alcohol and smoking cessation, dietary changes and exercise. According to Mohamed $e t a l,{ }^{24}$ out of 150 patients who reported as consumers of alcohol prior to hepatitis B diagnosis, $87.3 \%$ reduced the intake or stopped after knowing their status. About 57\% made healthier food choices and $46.6 \%$ increased their exercise activities. ${ }^{24}$ Although there is no evidence supporting dietary prescriptions for people with hepatitis B, many people resort to diet low in fat as a way of ensuring a healthy life.

This study had strengths and limitations. It is the first to explore the experiences of individuals with hepatitis B in Ghana and Africa. However, the small sample size makes the finding not generalisable to the entire people with hepatitis B in Ghana. In addition, the outcome of this study will assist in developing population-based surveys to quantify the extent of knowledge of people with hepatitis $\mathrm{B}$ in order to develop appropriate public health interventions in Ghana. The study is limited by the recruitment of only people within the age bracket of 26-45 years and few men participating in the study. Furthermore, the participants have lived with their diagnosis between 1 and 5 years.

\section{Conclusion}

The outcome of the study showed psychological and social challenges that persons with hepatitis B experienced right from the time of diagnosis throughout their life. It, therefore, suggests a more public health intervention that can critically respond appropriately to this burden currently confronting people with hepatitis B in Ghana. We, therefore, recommend integration of hepatitis B counselling (pretest and post-test counselling) in the already existing HIV structures. Furthermore, it is also important as a country to draw lessons from the process used in the diagnosis of HIV particularly, in ensuring that people provide consent for being tested.

Acknowledgements We acknowledge the contribution of the study participants.

Contributors CAA conceptualised the study. CAA, FN and ESD designed the study and the interview guide. Data were collected by CAA. Data analysis was done by FN, ESD and CAA. Manuscript was critically reviewed by FN and ESD. All authors read and approved the final manuscript.

Competing interests None declared. 
Patient consent Obtained.

Ethics approval Ethical clearance was obtained from Institutional Review Board of Noguchi Memorial Institute for Medical Research (Approval number NMIMR-IRB CPN 026/15-16). Permission was sought from the management of the data collection sites, and informed consent (written) was obtained from the participants.

Provenance and peer review Not commissioned; externally peer reviewed.

Data sharing statement Participants have consented for anonymised transcripts to be shared upon request.

Open Access This is an Open Access article distributed in accordance with the Creative Commons Attribution Non Commercial (CC BY-NC 4.0) license, which permits others to distribute, remix, adapt, build upon this work non-commercially, and license their derivative works on different terms, provided the original work is properly cited and the use is non-commercial. See: http://creativecommons.org/ licenses/by-nc/4.0/

(C) Article author(s) (or their employer(s) unless otherwise stated in the text of the article) 2017. All rights reserved. No commercial use is permitted unless otherwise expressly granted.

\section{REFERENCES}

1. Schweitzer A, Horn J, Mikolajczyk RT, et al. Estimations of worldwide prevalence of chronic hepatitis B virus infection: a systematic review of data published between 1965 and 2013. Lancet 2015;386:1546-55

2. Lozano R, Naghavi M, Foreman K, et al. Global and regional mortality from 235 causes of death for 20 age groups in 1990 and 2010: a systematic analysis for the Global Burden of Disease Study 2010. Lancet 2012;380:2095-128.

3. Trépo C, Chan HLY, Lok A. Hepatitis B virus infection. The Lancet 2014;384:2053-63.

4. Franco E, Bagnato B, Marino MG, et al. Hepatitis B: Epidemiology and prevention in developing countries. World $\mathrm{J}$ Hepatol 2012;4:74-80.

5. World Health Organisation (2014). Hepatitis B: key facts. World Health Organisation. http://www.who.int/mediacentre/factsheets/fs204/en/

6. Hu M, Chen W. Assessment of total economic burden of chronic hepatitis B (CHB)-related diseases in Beijing and Guangzhou, China. Value Health 2009;12 Suppl 3:S89-92.

7. Kavosi Z, Zare F, Jafari A, et al. Economic burden of hepatitis B virus infection in different stages of disease; a report from southern iran. Middle East J Dig Dis 2014;6:156-61.

8. Tu HAT, de Vries R, Woerdenbag HJ, et al. Cost-effectiveness analysis of Hepatitis B immunization in Vietnam: application of costeffectiveness affordability curves in health care decision making. Value Health Reg Issues 2012;1:7-14.

9. Cowie BC, Carville KS, MacLachlan JH. Mortality due to viral hepatitis in the Global Burden of Disease Study 2010: new evidence of an urgent global public health priority demanding action. Antivir Ther 2013;18:953-4.

10. WHO. Guidelines for the prevention, care and treatment of persons with chronichepatitis $B$ infection. Geneva, Switzerland: World Health Organisation, 2015. http://apps.who.int/iris/bitstream/10665/154590/ 1/9789241549059 eng.pdf (accessed 10 Jan 2017).

11. WHO. Global health sector strategy on viral hepatitis 2016-2021. Geneva, Switzerland, 2016. http://apps.who.int/iris/bitstream/10665/ 246177/1/WHO-HIV-2016.06-eng.pdf?ua=1 (accessed 17 June 2017).

12. WHO. SDG 3: Ensure healthy lives and promote wellbeing for all at all ages, 2017. http://www.who.int/sdg/targets/en/ (accessed 17 June 2017).

13. Merrill RM, Hunter BD. Seroprevalence of markers for hepatitis B viral infection. Int J Infect Dis 2011;15:e78-121.

14. National Aids Control Programme (2010). Guidelines for antiretroviral therapy in Ghana. http://ghanaids.gov.gh/gac1/pubs/Guidelines_for_ Antiretroviral_Therapy_in_Ghana_2010_NACP.pdf

15. Blankson A, Wiredu EK, Gyasi RK, et al. Sero-prevalence of hepatitis $B$ and $C$ viruses in cir-rhosis of the liver in Accra Ghana. Ghana Med J 2005;39:132-7.

16. Ghana Statistical Service (GSS), Ghana Health Service (GHS), and ICF International. Ghana Demographic and Health Survey 2014.
Rockville, Maryland, USA: GSS, GHS, and ICF International, 2015. https://dhsprogram.com/pubs/pdf/FR307/FR307.pdf

17. Adjei CA, Asamoah R, Atibila F, et al. Mother-to-child transmission of hepatitis B: extent of knowledge of physicians and midwives in Eastern region of Ghana. BMC Public Health 2016;16:537.

18. Alian S, Masoudzadeh A, Khoddad T, et al. Depression in hepatitis $\mathrm{B}$ and $\mathrm{C}$, and its correlation with hepatitis drugs consumption (interfron/lamivodin/ribaverin). Iran J Psychiatry Behav Sci 2013;7:24-9.

19. Arvand J, Shafiabadi A, Falsafinejad MR, et al. Depression in patients with chronic hepatitis $\mathrm{B}$ : an experience on individual solutionfocused therapy. Gastroenterol Hepatol Bed Bench 2012;5:166-8.

20. Cotler SJ, Cotler S, Xie H, et al. Characterizing hepatitis B stigma in Chinese immigrants. J Viral Hepat 2012;19:147-52.

21. Ellard J, Wallace J. Stigma and discrimination and hepatitis B: a review of current research. ARCSHS Monographs Series, 2013.

22. Guirgis M, Nusair F, Bu YM, et al. Barriers faced by migrants in accessing healthcare for viral hepatitis infection. Intern Med J 2012;42:491-6.

23. Modabbernia A, Ashrafi M, Malekzadeh R, et al. A review of psychosocial issues in patients with chronic hepatitis B. Arch Iran Med 2013;16:114-22.

24. Mohamed R, Ng CJ, Tong WT, et al. Knowledge, attitudes and practices among people with chronic hepatitis $\mathrm{B}$ attending a hepatology clinic in Malaysia: a cross sectional study. BMC Public Health 2012;12:601.

25. Ng CJ, Low WY, Wong LP, et al. Uncovering the experiences and needs of patients with chronic hepatitis B infection at diagnosis: a qualitative study. Asia Pac J Public Health 2013;25:32-40.

26. Grove SK, Burns N, Gray JR. Understanding nursing research. 7th ed. Philadelphia: Saunders, 2015.

27. Ghana Statistical Service (2013). Population and housing census regional analytical report-greater Accra Region, 2010. http:// www.statsghana.gov.gh/docfiles/2010phc/2010_PHC_Regional_ Analytical_Reports_Greater_Accra_Region.pdf (accessed 12 Aug 2015).

28. Tongco MDC. Purposive Sampling as a Tool for Informant Selection. Ethnobotany Research and Applications 2007;5:147-58.

29. Polit DF, Beck CT. Nursing research: principles and methods. 8th edn: Lippincot William \& Wilkins, 2014

30. Dahl TF, Cowie BC, Biggs BA, et al. Health literacy in patients with chronic hepatitis B attending a tertiary hospital in Melbourne: a questionnaire based survey. BMC Infect Dis 2014;14:1-9.

31. Nishimura A, Shiono P, Stier D, et al. Knowledge of hepatitis $B$ risk factors and prevention practices among individuals chronically infected with hepatitis B in San Francisco, California. J Community Health 2012;37:153-8.

32. ul Haq N, Hassali MA, Shafie AA, et al. A cross-sectional assessment of knowledge, attitude and practice among Hepatitis-B patients in Quetta, Pakistan. BMC Public Health 2013;13:448.

33. Wallace J, McNally S, Richmond J, et al. Managing chronic hepatitis $\mathrm{B}$ : a qualitative study exploring the perspectives of people living with chronic hepatitis B in Australia. BMC Res Notes 2011;4:45.

34. Wu H, Yim C, Chan A, et al. Sociocultural factors that potentially affect the institution of prevention and treatment strategies for prevention of hepatitis B in Chinese Canadians. Can J Gastroenterol 2009;23:31-6.

35. Ghana Statistical Service (2014). Ghana demographic health survey, 2014. http://www.statsghana.gov.gh/docfiles/DHS_Report/Ghana DHS_2014-KIR-21_May_2015.pdf (accessed 6 Aug 2015)

36. Mkandawire P, Richmond C, Dixon J, et al. Hepatitis B in Ghana's upper west region: a hidden epidemic in need of national policy attention. Health Place 2013;23:89-96.

37. Rafique I, Saqib MA, Siddiqui S, et al. Experiences of stigma among hepatitis B and C patients in Rawalpindi and Islamabad, Pakistan. East Mediterr Health J 2015:20:796-803.

38. Hajarizadeh B, Wallace J, Richmond J, et al. Hepatitis B knowledge and associated factors among people with chronic hepatitis B. Aust N Z J Public Health 2015;39:563-8.

39. Büssing $A$, Koenig HG. Spiritual needs of patients with chronic diseases. Religions 2010;1:18-27.

40. Gordon PA, Feldman D, Crose R, et al. The role of religious beliefs in coping with chronic illness. Couns Values 2011;46:162-74.

41. Tan NC, Cheah SL, Teo EK. A qualitative study of health-seeking behavior of Hepatitis B carriers. Singapore Med J 2005;46:6-10. 